\title{
Adam Smith e Francis Ysidro Edgeworth: \\ uma crítica do utilitarismo
}

Solange Regina Marin Professora da Universidade Federal de Santa Maria (UFSM)

André Marzulo Quintana Mestre em Economia Aplicada pela UFRGS

\section{Palauras-chave}

F. Y. Edgeworth, Adam Smith, filosofia moral, utilitarismo.

\section{Classificação JEL B10, B12,} B13.

\section{Keywords}

F. Y. Edgeworth, Adam Smith, moral philosophy, utilitarianism.

\section{JEL Classification B10, B12,} B13.

\section{Resumo}

Sugerimos, nesse trabalho, a investigação das concepções de Adam Smith e a de Francis Ysidro Edgeworth do utilitarismo. Ambas as concepções foram utilizadas para desenvolver a Ciência Econômica. Porém, também apresentaram as limitações da teoria econômica, cujas fronteiras vislumbradas pelos autores remetem para a necessidade de avaliar as ações e condutas humanas com teoria moral diferente do utilitarismo. Entendemos que a teoria moral de Adam Smith, esquecida pela história do pensamento econômico, se apresenta como alternativa e, em decorrência, uma ideia promissora para aperfeiçoar o estudo das ações e condutas ditas econômicas.

\section{Abstract}

We suggest, in this paper, the investigation of Adam Smith and Francis Y sidro Edgeworth's utilitarianism conceptions. Both conceptions were used in order to develop Economics as science. However, they presented the limitations of the economic theory, which boundaries recommended. 


\section{1_Introdução}

O utilitarismo tem sido teoria de larga influência na fundamentação das escolhas e decisões das ações e condutas humanas em sociedade. É especialmente influente na Ciência Econômica, presente nos fundamentos do comportamento econômico racional, aquele que permite o cálculo das decisões econômicas relevantes. Compreender o utilitarismo importa para conduzir os debates públicos de políticas sociais, definir a estrutura e o funcionamento do Estado, estabelecer as regras e as leis de alcance jurídico, impor a ação ou a conduta considerada moral nas relações sociais, bem como constituir a posição da maioria, do senso comum ou da opinião pública. ${ }^{1}$

O alcance da importância de reconhecer a ação ou conduta utilitária, e de quão ela é decisiva nas escolhas e decisões, pode ser compreendido a partir dos seus inúmeros defensores e também dos que a contestam. ${ }^{2} \mathrm{O}$ debate sobre o utilitarismo é sempre renovado, exigindo, ou posição em sua defesa, conferindo plausibilidade a essa teoria, ou a apresentação de alternativa para se pensar a teoria moral e orientar as ações e as condutas. Em algum momento, quando o pensador se depara com o problema mo- ral, convém se referir ao utilitarismo, ou para reconhecer nele a sua prevalência, ou para situá-lo como o principal oponente, como o fundamento a ser comparado, visando fortalecer algum outro princípio distinto da utilidade.

No curso desse debate moderno, entre utilitaristas e antiutilitaristas, ocorre diferenciação na fundamentação do que consiste a corrente, produzindo diversos conceitos e princípios. Por isso, nessa variedade de concepção, é preciso destacar qual o tipo de utilitarismo em questão, situar o debate em um princípio dessa corrente, visando contestá-lo e, se possível, no decurso da investigação, capacitar-se para a apresentação de um ponto de vista alternativo, seja em substituição de parte ou de todo o princípio enfocado, seja para apresentá-lo de forma mais compreensiva. A discussão da variedade de posições pode resultar na falta de especificação do que consiste a teoria normativa que leva esse nome e na tomada apressada dos seus fundamentos apenas como conceitos firmados na tradição científica.

Sugerimos, neste trabalho, a investigação de duas concepções do utilitarismo: a interpretação empreendida por Francis Ysidro Edgeworth (1845-1926),
"....] o utilitarismo constitui a base do pensamento ocidental, ou mais genericamente, de todo o pensamento moderno", conforme Caillé (1992). Tugendhat (2000, p. 353 e 357 ) considera que o utilitarismo leva vantagem sobre as outras teorias éticas por sua capacidade de cálculo da decisão, dispondo de um procedimento decisório objetivo, tema da teoria da escolha econômica. Refere-se ao utilitarismo como "a ideologia do capitalismo".

2 Entre os defensores, realçamos Hare (1998), Singer (2002) e Harsanyi (2002). Entre os críticos, destacamos Rawls (1997), Sen (1979, 1985, 1987 e 1999) e Nussbaum (2007). 
favorável à corrente, e a crítica de Adam Smith (1723-1790) ao uso do princípio da utilidade para fundamentar as ações e condutas, demonstrando notável posição antiutilitarista. Ambas as concepções, presentes na formação da Economia Política e da Economia Positiva, foram utilizadas para desenvolver a Ciência Econômica, porém também indicaram as limitações de uso dessa teoria moral. Pretendemos dar a entender que as fronteiras vislumbradas por F. Y. Edgeworth e as restrições ao princípio da utilidade identificadas por Adam Smith remetem para a necessidade de avaliação das ações e condutas humanas com teoria moral diferente do utilitaris- mo. Em conclusão, destacamos que a filosofia moral de Adam Smith, esquecida pela história do pensamento econômico, apresenta-se como alternativa e, em decorrência, promissora para aperfeiçoar o estudo das ações e condutas ditas econômicas, sobretudo porque a ética de Smith oferece a teoria moral mais abrangente, para além das limitações impostas pelo utilitarismo. ${ }^{3}$

Dividimos este artigo em três seções, além desta introdução. $\mathrm{Na}$ seção seguinte, descrevemos aspectos da formulação de F. Y. Edgeworth a respeito do utilitarismo clássico. $\mathrm{Na}$ outra seção, é exposta a crítica de Adam Smith ao princípio da utilidade como funda-

$\begin{array}{ll}3 \text { É conhecido o largo uso } & \begin{array}{l}\text { recente na obra de Amartya } \\ \text { Sen (notadamente em Sen, }\end{array} \\ \text { do utilitarismo na Ciência } & \text { 1987), reconhecendo a força } \\ \text { Econômica, especialmente } & \text { das objeções ao utilitarismo } \\ \text { no programa neoclássico de } & \text { apresentadas por Rawls, em } \\ \text { pesquisa, fundamentando o } & \text { 1971, ano de publicação de } \\ \text { indivíduo maximizador das } & \text { A Theory of Justice (Rawls, } \\ \text { preferências pessoais ditadas } & \text { 1997), bem como resgatando } \\ \text { pela possibilidade de obter } & \text { a filosofia moral de Adam } \\ \text { prazer e afastar a dor, ou } & \text { Smith. Com efeito, a obra de } \\ \text { conquistar a felicidade futura, } & \text { Smith tem sido reavaliada e } \\ \text { ou outra espécie de bem- } & \text { reinterpretada, notadamente } \\ \text { estar. Observe-se, contudo, } & \text { após a comemoração do } \\ \text { que a crítica ao uso dessa } & \text { bicentenário da publicação da } \\ \text { teoria moral para sustentar } & \text { Riqueza das Nações (publicada } \\ \text { cientificamente a Economia } & \text { em 1776), demonstrando } \\ \text { recebeu importante reforço } & \end{array}$

3 É conhecido o largo uso do utilitarismo na Ciência Econômica, especialmente no programa neoclássico de pesquisa, fundamentando o indivíduo maximizador das preferências pessoais ditadas pela possibilidade de obter prazer e afastar a dor, ou conquistar a felicidade futura ou outra espécie de bemestar. Observe-se, contudo, que a crítica ao uso dessa recebeu importante reforço que a sua ética tem sido negligenciada no estudo da Economia (Ver, por exemplo, Ganem, 2000; Cerqueira, 2004; Santos e Bianchi, 2007; Cerqueira, 2008 e Avila, 2009). No presente artigo, identificamos não só a desatenção quanto aos temas morais presentes nas obras de Smith e de Edgeworth, mas também a imprópria filiação de filósofo escocês como um dos precursores da tese utilitarista. Convém frisar ainda que este estudo pretende um entendimento sobre o utilitarismo, mediante a sua crítica, sem confrontar a fronteira do conhecimento da teoria econômica. Ou seja, filia-se, aqui, à perspectiva soft science de história do pensamento econômico (Arida, 2003), no sentido de contribuir para o resgate da ética de Smith, indevidamente associada ao utilitarismo, e de estimular a reincorporação dos temas morais nessa ciência. 
mento das avaliações e dos julgamentos das ações e condutas. A última seção é de considerações finais.

\section{2_ O utilitarismo segundo Francis Ysidro Edgeworth}

Duas razões nos levam a iniciar com a original interpretação do utilitarismo empreendida por Francis Y. Edgeworth. A primeira, por representar uma síntese do pensamento utilitarista clássico construído por Jeremy Bentham (1748-1832), John Stuart Mill (1806-1873) e Henry Sidgwick (1838-1900). A segunda razão, por acolher os avanços da economia neoclássica de William Stanley Jevons (1835-1882), Carl Menger (1840-1921), Léon Walras (1834-1910) e Alfred Marshall (18421924) como base científica para aperfeiçoar o utilitarismo. F. Y. Edgeworth interpretou a adesão positiva da Economia a esse sistema moral, mas conjecturou as limitações para o aperfeiçoamento dessa ligação. ${ }^{4}$

O utilitarismo clássico de J. Bentham associa essa corrente ética ao princípio de que a melhor ação é a que produz. 0 maior bem-estar social ou maior felicidade, ou seja, a melhor ação é a que é útil para melhorar o bem-estar ou a felicidade. Com as ideias subjacentes de buscar o prazer ou evitar a dor, como as forças que conduzem o indivíduo para esse maior estado de bem-estar, Bentham sugere o método de cálculo que leva em conta determinados valores (números cardinais) para as evidências dessas forças. As evidências são sensações de prazer e dor percebidas, variáveis em número, intensidade e duração. Esse cálculo hedonista, o balanço numérico entre os prazeres e as dores sentidas, permite apoiar as decisões das ações e condutas a serem adotadas pelos indivíduos, sem perder de vista o objetivo de maximizar a felicidade (Bentham, 1984, p. 16-8).

Para Sidgwick (1874), faltou a distinção entre o hedonismo universal e o hedonismo egoísta no princípio de Bentham. Em termos psicológicos, sempre permanecerá a dúvida quanto ao verdadeiro fim da ação, se por interesse próprio da felicidade ou do bem-estar individual, ou se por obrigação para com a felicidade ou o bem-estar geral. Em termos metodológicos, compete entender como se fará a contagem sugerida por Bentham na fórmula "every man to count for one, nobody for more than one". Sidgwick sugere considerar que a felicidade de uma pessoa seja contada tanto quanto a dos outros (iguais em grau), como um elemento da felicidade geral. Com
4 Ver Collander (2007) sobre a importância do estudo dos fundamentos da teoria da utilidade para o progresso do pensamento econômico, com base em F. Y. Edgeworth e I. Fisher. Sobre a teoria da utilidade e a Economia, ver Stigler (1950). 
isso, quando há conflitos nas comparações hedonísticas individuais, a felicidade universal, em que cada um conta com um elemento igual, constitui-se na ideia diretiva.

Somente a ideia diretiva de igualdade, porém, não é suficiente para garantir o direito. Falta o modo de se fazer os ajustes interpessoais nas situações de conflito. Quando se discute a repartição dos recursos para se alcançar a felicidade geral, algum critério de divisão é adotado, e esse critério deve ser reconhecido no grupo de participantes da divisão. Sidgwick, nesse caso, apenas tem a fórmula de Bentham, na qual a divisão deve ser feita em fatias iguais. Ficou indeterminado quanto à dicotomia felicidade geral versus felicidade individual, ou obrigações sociais versus interesse próprio, ou prudência versus benevolência. Considera mais apropriado o sistema utilitarista unicamente por fornecer um objetivo geral e consistente de decisão, não só para as ações hedonísticas individuais, como também para as ações e as regras a serem imputadas às instituições políticas, econômicas e de justiça da sociedade, ou seja, seguir o princípio de que a melhor ação é a que a maximiza a felicidade geral, computando-se igual felicidade para todos os participantes.
Todavia, é incerta a concordância social segundo esse princípio de igualdade, não só diante da variabilidade das opiniões pessoais acerca do que consiste a felicidade, como também diante de um estado final de máxima felicidade ou bem-estar geral que é mera idealização pessoal. Em termos psicológicos, ainda permanece a dificuldade em se distinguir se a ação humana é guiada pelo egoísmo, num extremo, ou pelo altruísmo perfeito, no outro extremo, ou qual seria o grau intermediário entre essas duas características. Sidgwick conhece que há entre as pessoas um grau de consideração pela felicidade universal, o que os leva a entender o comportamento dos outros, para além das decisivas considerações do interesse próprio. No entanto, a determinação do grau exato dessa consideração pelos outros depende de maior exame da teoria normativa.

A razão prática, conclui Sidgwick, está dividida entre extremos irreconciliáveis - o Dualism of Practical Reason - ou o indivíduo adota a própria ideia de felicidade máxima, ou se obriga no consenso acerca do que produz a máxima felicidade para o maior número de pessoas; pode-se dizer: ou age por interesse próprio, ou segundo o princípio do utilitarismo conectado ao hedonismo universal e ao 
igualitarismo. O dualismo não pode ser resolvido nos limites empíricos, já que não se pode obter prova para a conciliação entre o Utilitarian Duty e o princípio da felicidade geral, tampouco para a preponderância de um dos extremos. Essa conclusão de Sidgwick representa o drama das ações do senso comum (1874,

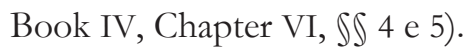

If then the reconciliation of duty and selfinterest is to be regarded as a bypothesis logically necessary to avoid a fundamental contradiction in one chief department of our thought, it remains to ask how far this necessity constitutes a sufficient reason for accepting this hypothesis. This, however, is a profoundly difficult and controverted question, the discussion of which belongs rather to a treatise on General Philosophy than to a work on the Methods of Ethics: as it could not be satisfactorily answered, without a general examination of the criteria of true and false beliefs. Those who hold that the edifice of physical science is really constructed of conclusions logically inferred from self-evident premises, may reasonably demand that any practical judgments claiming philosophic certainty should be based on an equally firm foundation. If on the other band we find that in our supposed knowledge of the world of nature propositions are commonly taken to be universally true, which yet seem to rest on no other grounds than that we have a strong disposition to accept them, and that they are indispensable to the systematic coherence of our beliefs, it will be more difficult to reject a similarly supported assumption in ethics, without opening the door to universal skepticism.

Sidgwick nos lega o utilitarismo como a recomendação de se incorporar o objetivo da máxima felicidade para o maior número de pessoas na sociedade, para além das decisões egoísticas, moldando a teoria moral para o grupo, e não apenas para o indivíduo. No entanto, não resolve a questão da distribuição dos recursos, permanecendo o critério de igualdade de Bentham. Conforma-se, ao final, com o indeterminismo dramático das ações cotidianas, ora egoísticas, ora altruísticas.

F. Y. Edgeworth retém esse final sugestivo de Sidgwick, de que o utilitarismo, como tese moral, ultrapassa o egoísmo puro, ainda que isso signifique, nas palavras de Sidgwick, num logical jugglery. O objetivo de Edgeworth é o mesmo de Sidgwick: demonstrar que o fim da ação utilitarista é a felicidade de todos, e não de tão somente um indivíduo em particular. Com isso, e também no intuito de aperfeiçoar o entendimento acerca do critério distributivo no utilitarismo, vale a pena acompanhar os passos de Edgeworth no dualismo da razão prática. 
Edgeworth não adota a exata fórmula de Fechner, mas uma função em que a derivada primeira é positiva e a segunda, negativa, já que incrementos de estímulos provocam aumentos cada vez menores das sensações. Essa redução das sensações constitui a base da então nascente economia marginalista.

6 A teoria dos jogos, que reúne racionalidade econômica e a então denominada psicologia-física, exatamente os mesmos temas que foram tratados por Edgeworth, constitui o reconhecimento atual da originalidade do seu pensamento. Ver também Marin e Quintana (2006).
No seu primeiro livro, New and Old Methods of Ethics or 'Physical Ethics' or 'Methods of Ethics' (1877), Edgeworth encontra no debate entre Alfred Barratt (1844-1881) e Sidgwick o fio condutor para discutir a indefinição quanto ao padrão para assegurar o bem-estar social entre os extremos - o egoísmo e o altruísmo. De plano, Edgeworth reconhece proveitoso o critério egoísta, concordando com Barratt, já que permite o uso dos métodos do que ele denomina de "psicologia-física" para identificar as noções de prazer e dor e quantificar os estímulos que visam ao bem-estar, de forma análoga ao que se percebe com as vibrações sonoras. Edgeworth segue a sugestão de Barratt, de que há evidência física do prazer obtido ou da dor evitada, que pode ser quantificada e apropriadamente tratada com o cálculo infinitesimal. Associada essa prova física à psicologia do egoísmo, segue a possibilidade de medição objetiva do prazer, deduzindo a intensidade das sensações da intensidade dos estímulos, com fundamento na Lei de Fechner (Edgeworth, 1877, p. 40-52). ${ }^{5}$

Esse primeiro momento, de evidência empírica do egoísmo natural com o prazer e a dor, e de introdução do cálculo das sensações por indivíduo, permite que Edgeworth, no seu segundo li- vro, o Mathematical Psychics, An Essay on the Application of Mathematics to the Moral Sciences (1881), filie-se ao cálculo econômico e contribua decisivamente para o programa de pesquisa em Economia Positiva. Edgeworth fundamenta o emprego das curvas de indiferença, do multiplicador de Lagrange, do diagrama de contrato (a "caixa de Edgeworth"), das curvas de contratos, colaborando com a "revolução marginalista" iniciada por seus contemporâneos W. S. Jevons, C. Menger, L. Walras, seguida por seu colega A. Marshall. ${ }^{6}$

Após dedicar as primeiras quinze páginas dessa obra ao enaltecimento do uso da Matemática nos fenômenos mecânicos, na Física, Edgeworth estabelece o Cálculo do Prazer, dividido em duas espécies - o Econômico e o Utilitário (1881: v). O Cálculo Econômico (1881, Parte II) é a análise matemática das manifestações dos estímulos egoístas que levam ao prazer ou que evitam a dor. $\mathrm{O}$ Cálculo Utilitário, por sua vez, compreende as análises interpessoais. O primeiro visa maximizar a utilidade individual, e o segundo, a utilidade universal.

Edgeworth (1881, p. 16) enuncia o primeiro princípio do cálculo econômico: "every agent is actuated only by self-interest". Se agir contra os outros, a ação pode ser 
denominada de "guerra" (war), do contrário, "contrato" (contract). Essas possibilidades dos agentes são desenvolvidas em um campo de competição apropriado (p.ex. o mercado), cujas propriedades, favoráveis ao cálculo matemático, são as multiplicidades e as divisões indefinidas, análogas ao infinito e ao infinitesimal do cálculo diferencial (Edgeworth,1881, p. 18). Entre dois extremos, de um lado, a guerra, cuja contratação é totalmente indeterminada, cada um ainda age por si, e, do outro lado, a competição perfeita, cuja contratação é plenamente determinada e a ação coletiva é única, paira a dúvida de um contrato mais ou menos indeterminado (Edgeworth,1881, p. 20). Como determinar a contratação na ausência da competição perfeita, segue Edgeworth, independe de determinar como se operam os embates e as concordâncias, já que se pode seguir o método empírico da inclusão de competidores adicionais no campo de competição (Edgeworth, 1881, p. 34): por exemplo, acordos entre o Robinson Crusoé e o Sexta-Feira, e, em seguida, com a participação dos seus clones (a caixa de Edgeworth).

Edgeworth privilegia a necessidade de descobrir um método para minimizar a indeterminação egoística. Entretan- to, mesmo com a inclusão, em pesquisa empírica, passo a passo de outros prováveis contratantes, dispostos a agir em sociedade para um determinado bem comum, a determinação somente pode ser alcançada com indivíduos homogêneos, na divisibilidade e no infinito, tal como previsto pelo apropriado método de cálculo. Ou o pior dos mundos, o egoísmo que indetermina contratos, ou o melhor, a competição perfeita. As situações pontuais, intermediárias, de conflitos interpessoais entre indivíduos heterogêneos, as condições de guerra, na linguagem de Edgeworth, ainda precisam ser entendidas e explicadas.

No segundo passo para resolver a dualidade proposta por Sidgwick, Edgeworth definitivamente ultrapassa o indeterminado egoísmo puro e sugere a importância de resolver os conflitos entre os contratantes com o princípio utilitarista. A passagem em que recomenda esse desconforto aos economistas, retirando-os da cômoda situação presumida pela competição perfeita, é elucidativa, como segue:

To impair, it may be conjectured, the reverence paid to 'competition'; in whose results - as if worked out by a play of physical forces, impersonal, impartial-economists have complacently acquiesced. Of justice and 
$\mathrm{Na}$ teoria dos jogos, o dilema do prisioneiro, que escolhe entre reduzir a sua pena e trair outro prisioneiro, constitui um marco na impossibilidade de se manter o critério egoísta, hedonista individual, usado pelo cálculo econômico, como origem para entender decisões e ações humanas. bumanity there was no pretence; but there seemed to command respect the majestic neutrality of Nature. But if it should appear that the field of competition is deficient in that 'continuity of fluid', that 'multiety of atoms' which constitute the foundations of the uniformities of Physics; if competition is found wanting, not only the regularity of law, but even the impartiality of chancethe throw of a die loaded with villainy economics would be indeed a 'dismal science', and the reverence for competition would be no more (Edgeworth, 1881, p. 50).

O cálculo econômico, fundado em indivíduos homogêneos, em ajustes contratuais entre indivíduos com o mesmo interesse, admitindo, portanto, que o egoísmo domina as ações humanas, permanece delineado e expressamente apropriado no outro extremo, quando é grande o número de contratantes, na competição perfeita, condição em que é permitido acolher com facilidade o princípio da igualdade de Bentham. No entanto, para avançar, onde são ponderados os conflitos e os contratos entre inúmeros indivíduos inter-relacionados - o cálculo com o princípio utilitarista -, então o cálculo econômico se revela limitado. Edgeworth alerta que:

The particles of an economic system neither cohere as a solid, nor collide with the inde- pendence of a gas. Their liquid movements are comparable to a dance in which youths and maidens move in unison; harmoniously, but subject a change of partners (Edgeworth, 1909, p. 369).

Diante do drama do dualismo da razão prática, representado por Sidgwick, e de egoístas em guerra, previsto do cálculo econômico, Edgeworth recorre ao princípio de arbitragem (principle of arbitration), definidor do ponto de concordância para ocorrer o contrato. Edgeworth retoma o dualismo entre as duas autoridades máximas - o egoísmo e o altruísmo - irreconciliáveis na razão prática, no sentido de Sidgwick, para assegurar que o único ajuste é requerido em algum ponto médio da curva de contrato. $\mathrm{Na}$ ausência de outro princípio convincente, o ajuste utilitário - o que maximiza a felicidade para todos - pode ser o selecionado (Edgeworth, 1881, p. 53-54).

Contudo, prevê Edgeworth, esse princípio de arbitragem, para atender "um mundo cansado de conflitos", tem que concorrer com o critério de justiça distributiva (Edgeworth,1881, p. 51). ${ }^{7} \mathrm{Na}$ primeira obra, a lei da distribuição de recursos entre os seres sensíveis seguiu a capacidade de sentir prazer, definido o coeficiente correspondente (análogo ao coeficiente " $k$ " na fórmula de Fechner). As- 
sim, a maior parte dos recursos (p. ex. riqueza) seria distribuída para o conjunto da população que possui poder de produzir efetiva ou potencialmente maior felicidade (felicific power). Na segunda obra, Edgeworth definiu esse poder no indivíduo que detém maior capacidade para felicidade (capacity for happiness) do que outro quando, planejada ou ocorrida a distribuição da mesma quantidade de recursos, o primeiro indivíduo obtenha a maior quantidade de prazer (Edgeworth, 1881, p. 57).

O critério distributivo envolve, então, reconhecer a "capacidade" para sentir prazer ou para irradiar felicidade. Entretanto, como distinguir o grupo ou os seres sensíveis mais ou menos capacitados para discutíveis ideias de felicidade ou de prazer? Edgeworth entende que, de geração em geração, dentro de uma mesma classe social, as preferências, que traduzem o maior prazer ou a maior felicidade, são transmitidas, capacitando a nova geração com as preferências testadas e acolhidas pelos antigos. Sendo assim, a capacidade tem relação com a cultura adquirida e é transferida segundo a educação social. $\mathrm{O}$ aperfeiçoamento social, no sentido de dotar os indivíduos de capacidade para otimizar o prazer ou a felicidade, o que deve deter- minar a distribuição dos recursos, torna-se uma situação cultural, em que indivíduos em sociedades ou classes sociais privilegiadas tendem a manter seus privilégios passados de geração em geração. Agora associado à tradição evolucionista, especificamente a estabelecida por Herbert Spencer (1820-1903), ${ }^{8}$ Edgeworth considera que, não só entre gerações, há aprendizado cultural, mas também no seio da atual cultura, desde que os participantes estejam imbuídos do objetivo que define o utilitarismo, ou seja, participar de tal forma que a felicidade do grupo a que pertence seja maximizada.

Edgeworth constata a impossibilidade de se pensar a distribuição igualitária quando se adota a ética utilitarista de Bentham (cada indivíduo conta por um, ninguém por mais de um). Também concorda que a razão prática recomenda a distribuição igualitária das utilidades, não só por interesse próprio (egoísta), mas em proveito de todos (altruísta), tal como estabelecido por Sidgwick. Contudo, ao final, produz um princípio de distribuição fundamentado em distinções culturais de classes sociais e de gênero humano (Edgeworth, 1881, p. 78), o que só nos indica que o cálculo utilitário permanece variável e indeterminado, a não ser que se defenda a supremacia de de-
Aqui se pode afirmar que o programa de pesquisa de Edgeworth é o método ético com o uso da Matemática, da Física, da Psicologia, da Biologia evolucionista e da Economia. 
9 Uemiya (2006) relaciona o evolucionismo de Edgeworth numa mistura de evolução segundo Herbert Spencer e de eugenia de Francis Galton (1822-1911).

10 Para uma discussão crítica da limitada racionalidade, ver, por exemplo, Sen $(1977,1994$ e 2005), Walsh (1994), Simon (1978) e Diesing (1950). terminada classe e de determinado gênero humano sobre os demais, seja qual for a característica escolhida. ${ }^{?}$

Ou seja, Edgeworth não encontra um consistente princípio de distribuição dos recursos no utilitarismo, ainda que tenha citado, sem aprofundar, o "meio termo aristotélico" e a "simpatia" como mecanismos neutralizadores das forças do egoísmo ao longo da curva de contrato (Edgeworth, 1881, p. 80). No entanto, embora reconhecido o obrigatório ajuste entre os contratantes, permanece incerto o critério de justiça distributiva. Em decorrência, Edgeworth deixa de assentar racionalmente esse princípio, mantendo a variabilidade da ideia de distribuição de recursos capazes de gerar a maior felicidade para o maior número de pessoas.

Ao final, fica apenas a indicação geral de que a competição requer o suplemento da arbitragem, e que a base da arbitragem, entre os contratantes autointeressados, é a máxima possibilidade da soma total da utilidade, o que seria resolvido no âmbito do Utilitarian Calculus (Edgeworth, 1881, p. 55-56), suposta certa diferença de capacidade para felicidade e para prazer, nos limites de uma dada classe social ou gênero.

Ocorre que o ajuste contratual, com base em uma concepção da justiça, somente pode ser compreendido no âmbito de uma ética que sustente o princípio ou critério escolhido, como suscitado por Sidgwick e também por Edgeworth. Mesmo com os esforços de Edgeworth de buscar a universalidade, não foi demonstrada a capacidade de o utilitarismo fundamentar a justiça distributiva. Permanece a fundação clássica do igualitarismo de Bentham, na teoria, e a distribuição desigual, na prática. A falta de um consistente princípio de justiça distributiva, considerando ainda a impossibilidade de assegurar se os contratantes visam à felicidade geral, concluímos que também permanece o irreconciliável dualismo da razão prática nos termos de Sidgwick.

Em suma, Edgeworth ressaltou a nítida especialização do Economicus Calculus, fixado no agente egoísta, maximizador da própria felicidade (e prazer), constituindo a limitada racionalidade econômica. ${ }^{10}$ Sugeriu expandir o conhecimento das relações interpessoais para o Utilitarian Calculus, em que são destacadas as diferenças entre os contratantes, exigindo o ajuste, contudo, por meio de uma justiça distributiva. No entanto, ainda que firmado o objetivo utilitarista de maximizar a felicidade para todos, ainda não encontramos no utilitarismo clássi- 
co um consistente critério de justiça distributiva. Permanece unicamente a recomendação de Sidgwick e de Edgeworth para a necessidade de se aprofundar no exame do fundamento moral.

Por ora, seguindo o referido por Edgeworth, de que as paixões egoístas são acalmadas pela simpatia, sugerimos o retorno ao iluminismo escocês, notadamente à teoria moral de Adam Smith. Esse retorno ao filósofo moral e economista aperfeiçoará nossa compreensão da teoria utilitarista e da possibilidade de sua crítica.

\section{3_A ética de \\ Adam Smith e a utilidade}

O que é útil, agrada, dá prazer, já foi enunciado nos sistemas morais dos iluministas escoceses, constituindo importante tema de fundamentação moral. ${ }^{11}$ Contudo, esses pensadores se preocuparam com doutrinas morais mais abrangentes do que a estrita maximização da felicidade, dando ênfase ao que seria, de fato, a origem do sentimento moral, a outros princípios. ${ }^{12}$ Como elaboraram profundas investigações e sistematizações da posição moral do indivíduo em sociedade, em teorias morais de largo alcance, a simples filiação desses pensadores escoceses como utilitaristas não lhes

faz justiça. Ou seja, não pertencem à corrente que, com base em Bentham, foi designada como "utilitarismo clássico". ${ }^{13}$

Como visto antes, Sidgwick e Edgeworth reconheceram a necessidade de investigar doutrinas morais abrangentes, a fim de melhor definir os acordos entre

${ }^{11}$ Sobre a contribuição dos pensadores escoceses para o iluminismo (Enlightenment) e, principalmente, para a filosofia moral, ver Robertson (1996) e Dow et al. (1998). Segundo Robertson, a filosofia britânica foi dominada pelo pensamento escocês, aproximadamente desde 1700 até 1850 , compreendendo mais de cinquenta pensadores reunidos em torno das universidades de Edinburgh, Glasgow e Aberdeen.

12 Por exemplo: o meio termo aristotélico (a temperança), de Lord Shaftesbury (1671-1713, terceiro conde), a benevolência como comportamento virtuoso recomendado, de Francis Hutcheson (1694-1746), a simpatia com o caráter útil, de David Hume (1711-1776), e a simpatia mediada pelo espectador imparcial, de Adam Smith. Observe-se ainda que todos criticaram os sistemas egoísticos de Thomas Hobbes (1588-1679) e Bernard Mandeville (1670-1733).

\author{
${ }^{13}$ É corrente considerar que o \\ "utilitarismo clássico" começa \\ com Bentham, em 1789, \\ ano de publicação de Uma \\ Introdução aos Princípios da \\ Moral e da Legislação. É notório \\ também identificar que J. S. Mill \\ criou o termo "utilitarismo", \\ em 1863, ano de publicação \\ de Utilitarianism. O princípio \\ da utilidade, que originou e \\ destacou essa teoria moral, \\ obteve sua versão mais \\ sofisticada na teoria moral de \\ David Hume e dos iluministas \\ escoceses, cabendo a Francis \\ Hutcheson, professor de \\ Filosofia Moral de Smith, \\ apresentar a fórmula geral \\ "a maior felicidade para o maior \\ número”, em 1765, na sua \\ obra Inquiry into the Origins of \\ our Ideas of Beauty and Virtue, in \\ Two Treatises. Por essa origem, \\ reconhecida, por exemplo, \\ na crítica de Rawls (1997), \\ denominamos aqui essa posição \\ de utilitaristas, e a oposta de \\ anti-utilitarista.
}


competidores e o critério da justa distribuição dos recursos. Não pretendemos aqui a discussão merecida e ampla desses temas - acordos sociais e distribuição justa. Nosso objetivo, por ora, é a crítica ao utilitarismo valendo-se das limitações fixadas por Edgeworth, sugeridas na seção anterior, e da posição manifestamente antiutilitarista de Adam Smith, agora em exposição.

Adam Smith parte de uma constatação empírica, a de que o senso comum valoriza mais a contemplação do ajuste exato dos meios para obter as comodidades e os prazeres do que as próprias comodidades e prazeres (Smith, 1999, p. 220). Sendo assim, não é a finalidade específica do objeto que agrada tanto, mas a sua disposição sistêmica, arranjado com perfeição e beleza, pronto para proporcionar o idealizado prazer. Dá exemplos: prefere-se arranjar as cadeiras desarrumadas do que sentar-se em uma delas para descansar; buscam-se acessórios frívolos (enfeites, adornos) os quais, pelo conjunto, dão aparência de que o possuidor, com eles, obtém prazer; admira-se mais a condição geral de riqueza, sem se importar com o que cada elemento dessa condição efetivamente proporciona (Smith, 1999, $4^{\text {a }}$, i).
É nessa busca de riqueza e honra que Adam Smith mostra a ilusão provocada pela aparência de beleza da utilidade. É o exemplo do árduo esforço do filho do pobre, com estudo, trabalho, dedicação, "servo de quem odeia e obsequioso a quem detesta", para, ao final, a velhice lhe revelar que as ideias de felicidade e tranquilidade, sempre naturalmente a sua disposição, constituem mera ilusão a partir da condição de riqueza e honra, e que aquelas ideias naturais foram perturbadas pelas penosas ações e condutas em busca dessa ilusão.

Durante toda a sua vida, persegue a ideia de certo repouso artificial e elegante, que talvez jamais alcance, e pelo qual sacrifica uma tranquilidade verdadeira que a todo tempo tem a seu dispor; repouso que, se nos extremos da velhice chega por fim a conquistar, descobrirá que não é, de modo algum, preferivel a essa humilde segurança e contentamento que abandonou por ele [...] finalmente começa a se dar conta de que riqueza e honra são meros enfeites frívolos [...] (Smith, 1999, p. 222).

O primeiro aspecto realçado por Adam Smith é que a felicidade e a segurança são condições da natureza humana; não precisam ser buscadas, somente perturbadas: "[... o o mendigo que se aquece ao 
sol junto da estrada possui a segurança por que se batem os reis" (Smith, 1999, p. 226).

O segundo aspecto é a felicidade imaginária medida segundo o ajuste exato dos meios para se atingi-la. Como se fosse um castelo de cartas, dá um trabalho para construir, e está sempre prestes a desmoronar:

Afastam as chuvas de verão, não a tempestade de inverno, mas a todo o tempo o deixam cada vez mais exposto à ansiedade, ao medo, e à dor; às doencas, à ira e à morte (Smith, 1881, p. 224).

Todavia, ressalva Adam Smith (Smith, 1999, p. 225), é exatamente essa ilusão que determina o movimento e a destreza dos indivíduos, que cultivou os solos, fundou as instituições promotoras do bem público, incitou o debate político e as relações comerciais. O utilitarismo conduz o ser humano para a ação prática.

Contudo, esse utilitarismo não consiste nas observações particulares dos objetos, mas na visão sistêmica. Não se sustenta que as estradas sejam melhoradas em solidariedade aos cocheiros condutores de carruagens, mas sim porque constitui mais um elemento de algum almejado sistema público de transportes (Smith, 1999, p. 227). Não se convence o administrador público com o argumento de que é preciso melhorar a habitação, a vestimenta e a alimentação para aprimorar o bem-estar dos mais necessitados.

É mais provável que o persuadas se descreveres o grande sistema de serviços públicos que trazem essas vantagens; se explicares as relações e as dependências entre as suas várias partes, sua subordinação mútua umas às outras, sua subserviência universal à felicidade da sociedade; se mostrares como esse sistema poderia ser introdurido no seu país, o que impede isso de ocorrer no momento, como se poderiam remover esses obstáculos, para que todas as várias rodas da máquina no governo pudessem se mover com mais harmonia e suavidade, sem raspar umas nas outras, sem retardar os movimentos umas das outras. É quase impossivel um homem ouvir um discurso como esse e não se sentir animado em alguma medida de espirito público (Smith, 1999, p. 228).

Isso significa dizer que condiz mais com o espírito público impulsionar a otimização da máquina imaginária que rege o sistema, do que incentivar a maximização da felicidade. Ou seja, as digressões políticas e econômicas envolvem mais a ordem sistêmica, a beleza da sua utilidade, do que a finalidade de melhorar o bem-estar social.

Ainda que a visão de arranjo dos meios de felicidade futura promova a ação humana na construção de proprie- 
dades, destacando indivíduos com maior movimento e destreza, e ainda que a felicidade dos cidadãos não seja o objetivo primordial do administrador público, que olha mais para a ordem do sistema, Smith lembra o provérbio - "os olhos são maiores do que a barriga" -, ou seja, a produção que excede a capacidade de consumo de um indivíduo é obrigatoriamente distribuída: os ricos são compelidos a dividir o produto de suas melhorias com os pobres,

[...] conduzidos por uma mão invisivel a fazer quase a mesma distribuição das necessidades da vida que teria sido feita, caso a terra fosse dividida em porções iguais entre todos os seus moradores; e assim, sem intenção, sem saber, promovem os interesses da sociedade... (Smith, 1999, p. 226).
Observe-se que essa forma não intencionada de justiça distributiva tem fundamento na ilusão sistêmica que confere a beleza da aparência de utilidade. Por isso, deve-se ter cuidado ao dar aqui um caráter geral à expressão "mão invisível", para não ser somente compreendida como a visão utilitária do sistema em ordem. ${ }^{14}$

$\mathrm{Na}$ Riqueza das Naçoes, Adam Smith descreve a ordem do sistema econômico com a percepção da beleza da utilidade, de onde se conclui pelo emprego do critério utilitarista nessa obra. ${ }^{15}$ No entanto, reiteramos que, para o autor, a concepção de indivíduos interrelacionados é mais ampla do que a simples percepção de beleza sistêmica, razão pela qual uma leitura da Riqueza das $\mathrm{Na}$ ções, ou uma apressada interpretação da
14 É uma metáfora para ilustrar que, a despeito do ser humano desejar ver a racionalidade como uma força motivacional, o movimento e flutuações das estruturas organizacionais são impostas sobre o indivíduo, sem que sejam de sua intenção ou conhecimento (Weinstein, 1997). A “mão invisível” é símbolo da obra de Adam Smith. Impressiona por admitir diversas interpretações: força da natureza, divindade, razão superior ou metáfora. Adam Smith menciona apenas uma vez em cada obra para indicar que outros objetivos são alcançados, mesmo que não tenham sido intencionados. Nozik (1974) analisa essas ideias de "consequência não intencionada da ação humana" e "ordem espontânea". Para uma análise com a ideia estoica de desígnio natural, ver Denis (1999). Sobre os vários tipos de “mãos invisíveis" ver Ahmad (1990) e Davis (1990). Para a visão sistêmica, ver Prado (1992).

15 Sobre o utilitarismo na obra de Adam Smith, ver Campbell e Ross (1981) e Nelson (1999). Campbell e Ross confirmam que Smith é hostil à utilidade como uma explanação da origem das regras morais ou como princípio para aplicação rotineira. No entanto, para esses autores, Smith recorre ao critério da utilidade - a maximização da felicidade - na avaliação de práticas, instituições e sistemas (social, político ou econômico) na Riqueza das Nações. Por isso que os autores recomendam considerar mais o aspecto contemplativo do que o lado prático do utilitarismo de Smith. 
"mão invisível", unicamente com a ótica utilitarista, confere um entendimento limitado da Economia Política descrita nessa obra. ${ }^{16}$

Adam Smith elabora um sistema moral mais abrangente, fundado antes na conveniência das ações e condutas, no exame dos motivos, e depois no entendimento do sistema organizado unicamente nos méritos das ações e condutas, na análise das consequências, como sugere o utilitarismo. $\mathrm{Na}$ sua ética, primeiro, o que comanda as posições, decisões e julgamentos são os motivos das ações e condutas. As consequências das ações e condutas, os resultados, as finalidades, são secundárias na análise. Portanto, a ética de Smith, diferentemente da dos utilitaristas, não é consequencialista. ${ }^{17}$

Para examinar os motivos das ações e condutas, precisamos avaliar a situação contingente. Dois aspectos aqui merecem destaque. Primeiro, avaliamos as circunstâncias que envolvem pessoas inter-relacionadas. Não há o que analisar quando o indivíduo está só, em estado natural de egoísmo. Ele segue unicamente o seu gosto ou o seu desejo pessoal. Por isso que, reiteramos, a ética, de maneira geral, tem base nas relações sociais, tornando sem sentido as análises que partem do egoísmo. Nesse aspecto, de ampla rejeição do egoísmo no pensamento iluminista escocês, decorre também a insubsistência de aplicação do dualismo da razão prática de Sidgwick na teoria moral.

O segundo aspecto é a particularidade da situação que lhe dá a contingência. A visão sistêmica oriunda da aparência da utilidade dá uma ideia geral, vaga e indeterminada. Somente exemplos de casos particulares realçam a conveniência da ação ou conduta.

Seja qual for o método de avaliação, no sistema de Adam Smith a conveniência da ação ou conduta é percebida quando se procura compatibilizar sentimentos - a simpatia entre o agente, o paciente e os espectadores - o que somente pode ser sentido entre indivíduos inter-relacionados em certa situação particular.

Assim, a vantagem de ser rico e grandioso, na magnificência da sua situação, está no fato de essa condição ser alvo das emoções dos outros, ser sentida de forma compartilhada pelos envolvidos, à vista da ampla simpatia, satisfazendo o amor à distinção tão natural ao ser humano. Tal disposição, na perspectiva dos sentimentos do espectador, não parte da própria pessoa, ou seja, prevalece a consideração de como a situação se
16 A concepção de que, na Teoria dos Sentimentos Morais, o ser humano simpático é altruísta ou benevolente, enquanto, na Riqueza das Nações, o princípio do interesse próprio mostra um indivíduo egoísta, foi elaborada por pensadores da Escola Histórica alemã e ficou conhecido como o Das Adam Smith Problem. Sobre esse tema, ver Bianchi (1988) e Ganem (2000). Sobre a necessidade de teoria moral na Economia, ver Collard (1988). Ver também Sen (1987) sobre a importância da relação entre economia e teoria moral.

17 A ética de Smith é diferente das éticas de David Hume e Francis Hutcheson que fundamentaram o julgamento moral em considerações de estética e de agente-neutro, ou seja, é moral beauty.

Adam Smith considera que o primeiro julgamento moral é o do senso de conveniência e não uma forma de beleza. É o que ele chama de propriety, seja do motivo de um agente, seja do sentimento de um paciente. A esse respeito, ver

Darwall (1999). 
mostra aos olhos dos outros. Nessa situação, como em todas as outras que definem a aprovação ou desaprovação dos objetos morais, são levados em conta os sentimentos compartilhados dos espectadores. Não é a forma que se visualiza a utilidade "a primeira ou principal fonte de nossa aprovação ou desaprovação" (Smith, 1999, p. 230). Não é possível que os espectadores avaliem a condição de riqueza da mesma forma como aprovam um

edifício cômodo e bem projetado; ou que não tenhamos outra razão para elogiar um homem que não seja a mesma pela qual recomendamos um armário com gavetas (Smith, 1999, p. 231).

Não pode partir do gosto pela beleza da utilidade o mesmo sentimento que aprova a virtude e desaprova o vício humano.

No sistema ético de Adam Smith, o critério do utilitarismo é o mesmo pelo qual se aprova uma máquina bem engendrada, enquanto a aprovação ou desaprovação dos caracteres e ações humanas deve ser vista na ótica do espectador imparcial (Smith, 1999, p. 406-407).

Quando os objetos contemplados não têm relação particular conosco, concordamos apenas com o bom gosto e o discernimento demonstrados. Assim, um cálculo matemático elegante, um dis- curso bem composto, pede um julgamento estético, já que o seu conteúdo não parece afetar a nossa vida particular. Quando o objeto, porém, afeta a nossa vida privada, então surge a necessidade de compatibilizar a sua conveniência. No primeiro caso, a beleza das aparências da "grande máquina do universo" afeta indistintamente os envolvidos, sendo mais fácil compartilhar ideias sobre a utilidade dos objetos. Mas, no segundo caso, quando, por exemplo, alguém se sente ofendido por algum motivo particular, requer que seu ressentimento seja compartilhado pelo espectador, tornando as relações interpessoais mais complexas. O afetado agora clama pelos motivos da ação ou conduta, o fundamento da aprovação moral, relegando ao segundo plano a aparência de utilidade do objeto (Smith, 1999; $1^{a}$ parte, seção I, iv).

Portanto, enquanto o julgamento da utilidade do objeto é a contemplação de sua beleza, o julgamento moral requer mais; exige a emoção compartilhada com o motivo da ação ou conduta. $\mathrm{Ou}$, nos termos da teoria de Adam Smith, requer a simpatia do espectador com os motivos do agente.

O critério utilitarista se amolda ao comportamento egoísta, à visão de sistema bem engendrado, ao olhar abrangen- 
te, mas não tem poder de decisão entre indivíduos inter-relacionados, em situações particulares. Ou seja, não é promissor para entender as interações pessoais. Além disso, não há como extrair dessa concepção do utilitarismo, tal como descrita por Adam Smith, uma base segura para assentar a justiça das relações, ratificando a indeterminação do critério distributivo já percebido na seção anterior deste artigo.

Ainda que se possa convencer o administrador do sistema, expondo-lhe os diversos mecanismos que dão aparência de utilidade, ainda assim o seu funcionamento dependerá das interações pessoais, quando ocorrem as trocas de emoção com a avaliação da conveniência dos atos e condutas. Ainda que essa descrição da aparência da utilidade do sistema seja o método científico empregado para dar movimento nas ações humanas, não se pode olvidar das relações morais que delimitam o comportamento humano então envolvido.

Para adaptar o comportamento humano, definindo o princípio de arbitragem, nos termos de Edgeworth, Adam Smith sugere interpor entre os indivíduos relacionados o julgamento do espectador imparcial, aquele habitante dentro do peito presente entre todos os que compartilham a emoção, constituindo a razão imparcial que dá sentido ao mérito ou demérito da ação (Smith, 1999, p. 84, 159 e 365). Contudo, há muito que investigar na teoria moral de Adam Smith, além da suposta racionalidade do espectador imparcial, como a justiça com base no ressentimento do sofredor da ação, a origem natural dos sentimentos, os estados normais de felicidade e tranquilidade do ser humano e o elenco de virtudes e vícios.

Por ora, neste artigo, afirmamos a sua posição manifestamente antiutilitarista, ou seja, a de que a utilidade não institui a origem das aprovações morais, apenas concede a aparência de beleza ao sistema imaginado, o que permite prever a possibilidade de obter maior felicidade, uma ilusão que movimenta o indivíduo e a sociedade. Aqui, Adam Smith deixa um desafio: a sociedade não se dissolve quando está ausente a benevolência, uma vez que tem o senso de utilidade, sem qualquer amor ou afeto recíproco, "uma troca mercenária de bons serviços, segundo uma valoração acordada entre eles" (Smith, 1999, p. 107). O desafio consiste em refletir se a nossa vida é guiada apenas pela troca mercenária de bens e serviços ou se também é decisivamente moldada pela simpatia do espectador imparcial. 


\section{4_Considerações finais}

Nosso objetivo neste artigo foi oferecer uma compreensão do utilitarismo como teoria do princípio da ação e conduta do ser humano para além da ideia diretiva de maximizar a felicidade social. Partimos da elucidativa interpretação de Edgeworth, com a original análise do utilitarismo clássico, que reúne o desenvolvimento contemporâneo da Matemática, da Física, da Psicologia, da Biologia e da Economia para o conhecimento do método ético, estabelecendo os limites para uma crítica ao utilitarismo, ou seja, a obstrução de desenvolvimento dessa teoria diante do irreconciliável dualismo da razão prática, bem como da impossibilidade de se conhecer os acordos entre indivíduos inter-relacionados e de fixar o critério de justiça distributiva. Na sequência, destacamos a possibilidade de, com Adam Smith, compreender o utilitarismo como comportamento contemplativo de uma beleza sistêmica, constituindo mera questão de gosto pessoal, existindo outras fontes de aprovação moral a serem investigadas.

Ainda que essa compreensão e crítica do utilitarismo necessitem avançar com o desenvolvimento de concepções posteriores dessa tese, o resultado mais importante é que o sistema moral de Adam Smith se apresenta como importante alternativa para se pensar as relações interpessoais.

Recomendamos que a Economia Política de Adam Smith, fundada na $\mathrm{R} i$ queza das Nações, seja pensada em termos da ampla teoria moral contida na Teoria dos Sentimentos Morais. Sugerimos que a Ciência Econômica, como um todo, não só a parte da Economia Normativa (Economia do Bem-Estar, Teoria da Escolha), mas também a denominada Economia Positiva (Teorias do Consumidor e do Produtor, Teoria dos Jogos), mereçam reflexões em termos de uma ética abrangente.

Sem o egoísmo para justificar a origem das ações e condutas humanas em sociedade, e considerando que prazer, dor e um imaginário estado final de felicidade são medidos segundo a ótica particular, e constituídos a partir da percepção de beleza dos meios e recursos para atingi-los, o utilitarismo perde o elemento de otimização, fragilizando o entendimento do princípio de maximizar a felicidade.

Uma vez que o utilitarismo, tal como aqui exposto, não permite compreender adequadamente as relações interpessoais, os conflitos e os acordos entre os participantes, as motivações práticas 
dos envolvidos, a gratidão e o ressentimento dos indivíduos inter-relacionados, não encontramos fundamento nessa teoria para se discutir a justiça distributiva. Até onde chega Edgeworth, restaria apenas a fórmula de Bentham, compondo mais um artifício de cálculo do que um critério distributivo. Isso fragiliza o entendimento de como estender a felicidade para todos.

Concordamos com Edgeworth no sentido de que se pense no aperfeiçoamento da Ciência Econômica com a supressão do caráter egoísta como fundamento. Discordamos, contudo, quanto ao emprego do utilitarismo para essa tarefa. Por isso, convém pensar num retorno à filosofia moral do patrono da Economia. E, por todo o exposto, conjecturamos que faz falta para a Ciência Econômica a teoria dos sentimentos morais. 


\section{Referências bibliográficas}

\author{
AHMAD, Syed. Adam Smith's \\ four invisible hands. History of \\ Political Economy, Durham, v. 22, \\ n. 1, p. 137-144, 1990. \\ ARIDA, Persio. A história do \\ pensamento econômico como \\ teoria e retórica. In: REGO, J. M. \\ (Ed.). Retórica na Economia. São \\ Paulo: Editora 34, 2003.
}

AVILA, Rober I. Do homem smithiano ao homo economicus: egoísmo e dissolução da moral.

In: ENCONTRO NACIONAL DE ECONOMIA. 37., 2009. Foz do Iguaçu. Anais... Foz do Iguaçu: ANPEC, 2009. Disponível em: <http://www.anpec.org.br/ encontro_2009.htm>. Acesso em: 2 jan. 2010

\section{BENTHAM, Jeremy. Uma}

introdução aos princípios da moral e da legislação. São Paulo: Abril Cultural, 1984. (Tradução de Luiz João Baraúna. Coleção Os Pensadores).

BIANCHI, Ana Maria. O (presumido) paradoxo de Adam Smith, moralista e pai da Economia. Literatura Econômica, Rio de Janeiro, v. 10, n. 1, p. 3-28, 1988.

CAILLÉ, Alain. Utilitarianism and anti-utilitarianism. Thesis Eleven, n. 33 , p. $57-68,1992$.
CAMPBELL, T. D.; ROSS, Ian S. The utilitarianism of Adam Smith's policy advice. Journal of the History of Ideas, v. 42, n. 1, Jan.-Mar. 1981.

CERQUEIRA, Hugo. Adam Smith e o surgimento do discurso econômico. Revista de Economia Política, v. 24, n. 3 , p. 422-441, 2004.

CERQUEIRA, Hugo. Sobre a filosofia moral de Adam Smith. Sintese - Revista de Filosofia, v. 35, p. $57-86,2008$.

\section{COLLANDER, David.}

Retrospectives Edgeworth's hedonimeter and the quest to measure utility. Journal of Economic Perspectives, v. 21, n. 1, 2007.

COLLARD, David A. A new moral sentiments? A review (wellbeing: Its meaning, measurement and moral importance). Oxford Economic Papers, v. 40, n. 2, p. 289-295, 1988 .

DARWALL, Stephen. Sympathetic liberalism: Recent work on Adam Smith. Philosophy and Public Affairs, Princeton, v. 28, n. 2, p. 139-164, 1999.
DAVIS, J. Ronnie. Adam Smith on the providential reconciliation of individual and social interests: is man led by an invisible hand or misled by a sleight of hand? History of Political Economy, Durham, v. 22, n. 2, p. 341-352, 1990

DENIS, Andy. Collective and individual rationaly in economics: The invisible hand of God in Adam Smith. Nov. 1999. Disponível em: $<$ http://www.city.ac.uk/andy/ research>. Acesso em: 5 dez. 2008.

DIESING, Paul. The nature and limitations of economic rationality. Ethics, v. 61, n. 1, p. 12-26, 1950.

DOW, Alexander; DOW, Sheila; HUTTON Allan et al. Traditions in thought: the case of Scottish political economy. New Political Economy, Abingdon, v. 3, n. 1, p. 45-58, 1998.

EDGEWORTH, Francis Y. New and old methods of ethics or 'physical ethics' or 'methods of ethics'. In: Mathematica Psychics and Further Papers on Political Economy. Ed. Newman, Peter. Oxford and London, 1877. James Parker and Co. Disponível em: <http:// books.google.com.br/books $>$. Acesso em: 2 dez. 2008.
EDGEWORTH, Francis Y.

Mathematical Psychics: an essay on the application of Mathematics to the moral sciences. London: Kegan Paul, 1881

Disponível em: < http:// socserv2.socsci.mcmaster. $\mathrm{ca} / \sim$ econ/ugcm/3113/edgeworth/ mathpsychics.pdf $>$

Acesso em: 2 dez. 2008.

EDGEWORTH, Francis Y. The Theory of Distribution. Quaterly Journal of Economics. 1909. Disponível em: < http://socserv. mcmaster.ca/ econ/ugcm/3113/ edgeworth/Distribution.pdf $>$. Acesso em: 2 dez. 2008

GANEM, Angela. Adam Smith e a explicação do mercado como ordem social: uma abordagem histórico-filosófica. Revista de Economia Contemporanea, Rio de Janeiro, v. 4, n. 2, p. 9-36, 2000.

HARE, R. M. Ética: problemas e propostas. São Paulo: Ed. UNESP, 1998.

HARSANYI, John C. Morality and the theory of rational behaviour. In: SEN, Amartya; WILLIANS, Bernard. (Ed.). Utilitarianism and beyond. Cambridge: Cambridge U. P., 2002. p. 39-62. 
MARIN, Solange; QUINTANA, André M. A transformação marginal na teoria do valor dos primeiros neoclássicos. Cadernos de Economia, Chapecó, v. 19, p. $115-138,2006$

\section{NELSON, William H.}

Utilitarianism in Adam Smith's Theory of Moral Sentiments. Studies in social and political thought. Issue 1. 1999. Disponível em: < http://www.sussex.ac.uk/cspt/ documents/issue1-2.pdf $>$. Acesso em: 8 dez. 2008.

NOZIK, Robert. Invisible-hand explanations. American Economic Review, Princeton, v. 84, n. 2, p. 314-318, 1974

NUSSBAUM, Martha C. Frontiers of justice: disability, nationality, species membership. London: Belknap Press, 2007.

PRADO, Eleutério F. S. Ação e ordem social em Locke e Smith. Estudos Econômicos, v. 22, n. 3, p. 375-391, 1992.

RAWLS, John. Uma teoria da Justica. São Paulo: Martins Fontes, 1997. Trad. Almiro Pisetta e Lineta Esteves.

ROBERTSON, John. The Scottish contribution to the enlightenment. Electronic Seminars in History. 1996. Disponível em: <http://ihr. sas.uk/ihr/esh/eshmnu.html>. Acesso em: 2 dez. 2008.

SANTOS, Antônio Tiago L. A. dos; BIANCHI, Ana Maria. Além do cânon: mão invisível, ordem natural e instituições. Estudos Econômicos, São Paulo, v. 37, n. 3, p. 635-662, 2007.
SEN, Amartya. Rational fools: A critique of the behavioral foundations of Economic Theory. Pbilosopby and Public Affairs, v. 6, n. 2, p. 317-344, 1977.

SEN, Amartya. Utilitarianism and Welfarism. The Journal of Philosophy, v. 76, n. 9, p. 463-489, 1979.

SEN, Amartya. Well-being, agency and freedom (the Dewey Lectures, 1984). The Journal of Philosophy, v. 82, n. 4, p. 169-221, 1985.

SEN, Amartya. On etbics and economics. New York: Basil Blackwell, 1987.

SEN, Amartya. The formulation of Rational Choice. The American Economic Review, v. 84, n. 2, p. 385-390, 1994.

SEN, Amartya. Development as freedom. New York: Anchor Books, 1999.

SEN, Amartya. Why exactly is commitment important for rationality. Economics and Philosophy, v. 21 , p. $5-13,2005$

SIDGWICK, Henry. Methods of Ethics. 1874. Disponível em: $<$ http://www.laits.utexas.edu/ poltheory/sidgwick/me/index. html>. Acesso em: 5 dez. 2008.

SIMON, Herbert. Rationality as process and as product of thought. The American Economic Review, v. 68, n. 2, p. 1-16, 1978.

SINGER, Peter. Ética prática. São Paulo: Martins, 2002.
SMITH, Adam. Teoria dos Sentimentos Morais. São Paulo: Martins Fontes, 1999. (Tradução Lya Luft; Revisão

Eunice Ostrensky).

STIGLER, George. The development of Utility Theory. (2 parts.) Journal of Political Economy, Part 1, v. 58, n. 4, p. 307-327; Part 2, v. 58, n. 5, p. 373-396, 1950.

TUGENDHAT, Ennst. Lições sobre ética. Petrópolis: Vozes, 2000.

UEMIYA, Tomoyuki. F. Y.

Edgeworth's Mathematical Psychics and his utilitarianism; the origin of his thought in the Sidgwick-Barratt Controversy. School of Economics, Kwansei Gakuin University in its series with number 37. 2006. Disponível em: < http://192.218.163.163/

$\mathrm{RePEc} / \mathrm{pdf} / \mathrm{kgdp} 37 . \mathrm{pdf}>$. Acesso em: 15 dez. 2008.

WALSH, Vivian. Rationality as self-interest versus rationality as present aims. The American Economic Review, v. 84, n. 2, p. 401-405, 1994.

WEINSTEIN, Jack Russel. Critical thinking and the moral sentiments: Adam Smith's Moral Psychology and contemporary debate in critical thinking and informal logic. inquiry: Critical thinking across the disciplines, Califórnia, v. 16, n. 3, p. 78-91, 1997. Disponível em: < http:// zimmer.csufresno.edu. Acesso em: 10 dez. 2008.

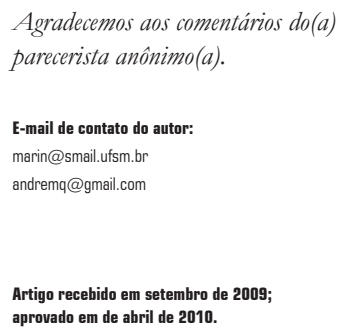

